\title{
A Simulation-Based Procedure to Determine Optimum Range of Settings of Fast Valving Action of Steam Turbines to Enhance Frequency Stability
}

\author{
K.J. Lakmewan, D. Prasad Wadduwage and D.G.R. Fernando
}

\begin{abstract}
Fast Valving (FV) mechanism of steam turbines is considered to be one of the most effective actions for enhancing the security of a power system subsequent to disturbances. It plays a significant role in mitigating the impact of severe disturbances by instantly decreasing steam turbine power, thus ensuring the power system stability. There is a direct relationship between the settings of Over-Speed Protection Control (OPC) unit of steam turbines and the control functions of FV. This paper proposes a generalized simulation-based procedure to determine the optimum intermediate valve actuation timings of the FV control action. A coal-fired thermal power plant has been used as the case study and the accuracy of the settings made using the proposed approach has been demonstrated using actually happened contingencies in a real power system. Finally, it is concluded that the proper selection of actuation timings of intermediate valves for FV scheme has a significant effect on enhancing frequency stability under transient conditions.
\end{abstract}

Keywords: $\quad$ Fast Valving (FV), Over-Speed Protection Control (OPC), Power System (PS), Large Disturbances, Optimum Time Settings, Transient Stability

\section{Introduction}

Today's world is highly dependent on electricity due to growth of needs and increased number of electrical appliances. Therefore, the requirement to maintain a healthy and a reliable power system is much important now than ever. Hence significant attention has been drawn to the topic of power system stability and various research studies are being conducted in this field.

Transient stability is the ability of a power system to maintain synchronous operation subsequent to large-magnitude disturbances such as tripping of elements due to three-phase faults [1]. Fast Valving (FV) action of a steam turbine is an accepted practice to enhance the transient stability of a power system [2]. FV control is rising in prominence as a preventive control action since power systems are presently operating near their stability limits and also due to difficulties in expanding the transmission system. Further, FV is considered to be a cost effective method to enhance the transient stability of a power system [3].

During an FV action, the turbine mechanical input power is decreased when the turbine speed is increased beyond the predefined limits. Rapid closing and opening of steam valves is activated in a prescribed manner to reduce the turbine acceleration following a severe fault in a power system. Here the Intercept Valves (IV) of the steam turbines are fast closed, resulting in rapid reduction of mechanical power. This action must be initiated within a minimum time after the detection of a disturbance in the power system, followed by its reopening.

Impact of FV action can be explained using the relationship between output electrical power and the rotor angle of a synchronous generator connected to a large power system. Figure 1 shows these relationships in three stages: prefault condition (curve 1), during-fault condition (curve 2), and post-fault condition (curve 3) [4].

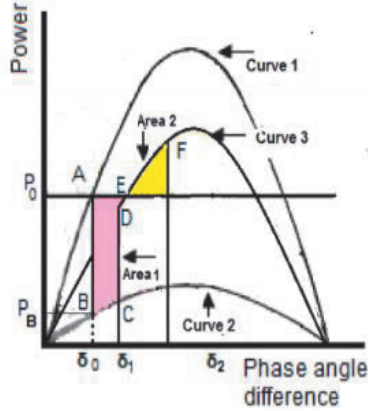

(a)

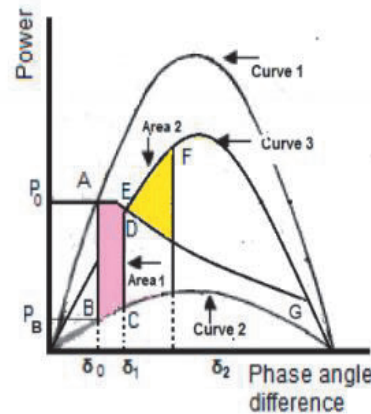

(b)
Figure 1 - Power Angle Curves for Transient Stability, (a) without FV, and (b) with FV [4]

Eng. K.J. Lakmewan, AMIE(SL), B.Sc. Eng. (Hons.) (Moratuwa), M.Sc. (Moratuwa), Electrical Engineer, Ceylon Electricity Board. Email:janakalakmewan@gmail.com

(1D http://orcid.org/0000-0003-4288-3633

Dr. D. Prasad Wadduwage, B.Sc. Eng. (Moratuwa),

Ph.D. (Manitoba), MPhil (Moratuwa), Senior Lecturer, Department of Electrical Engineering, University of Moratuwa.Email:prasadwd@uom.lk

(ib) http://orcid.org/0000-0001-9091-8170

Eng. D.G. Rienzie Fernando, C.Eng, MIE (SL), B.Sc. Eng. (Hons.) (Moratuwa), Managing Director, Amithi Power Consultants (Pvt) Ltd. Email:rienziefdo@gmail.com

(i) http://orcid.org/0000-0001-9921-3054 
During the steady state operation, the power system is operated at equilibrium point $\mathrm{A}$ in curve 1 as shown in Figure 1(a). The electrical power is dropped to the point $B$ due to a large disturbance of the system but mechanical input power remains constant at $\mathrm{P}_{\mathrm{o}}$ as illustrated. This causes to accelerate the machine until the operating point reaches point $C$ in curve 2 of Figure 1(a) at which the fault is cleared up, thereby shifting the operating point to point $\mathrm{D}$ in curve 3 . The accelerating area (Area 1) and the decelerating area (Area 2) represent the energy gained during the transient period and the energy that can be released back to the network, respectively. The system is stable if the accelerating area (Area 1) is less than or equal to the decelerating area (Area 2) as per the equal area criterion [1].

When the FV action is incorporated, input power is changed in accordance with the curve AG of Figure 1(b). Now, the FV operation helps the decelerating area (Area 2) to increase and accelerating area (Area 1) to decrease, thereby increasing the probability of being in synchronism subsequent to the contingency. The shape of the curve AG when FV is incorporated will be determined by the valve opening and closing sequences and whether the valves remain closed or open.

Valve closing and opening sequences of $\mathrm{FV}$ scheme is shown in Figure 2. Upon the detection of pre-set speed of steam turbine following a severe power system disturbance, a signal will be generated to close the IVs controlling the steam to the turbine at a pre-set rate, hold them closed for an adjustable period of time and then to reopen the same again at a pre-set rate. These settings of a given unit must be made carefully, based on a proper system study. Therefore, the main objective of this paper is to present a simulation-based generalized procedure to determine the optimum valve actuation timings so as to maintain the system stability.

The procedure and the results are demonstrated using a coal-fired thermal power plant as a case study. The remaining sections of this paper are organized as follows. Section 2 elaborates the importance of proper selection of the valve timings based on practical experience in the Sri Lanka power system. The proposed simulation-based procedure is explained in Section 3. The results and conclusions are given in Sections 4 and 5 respectively.

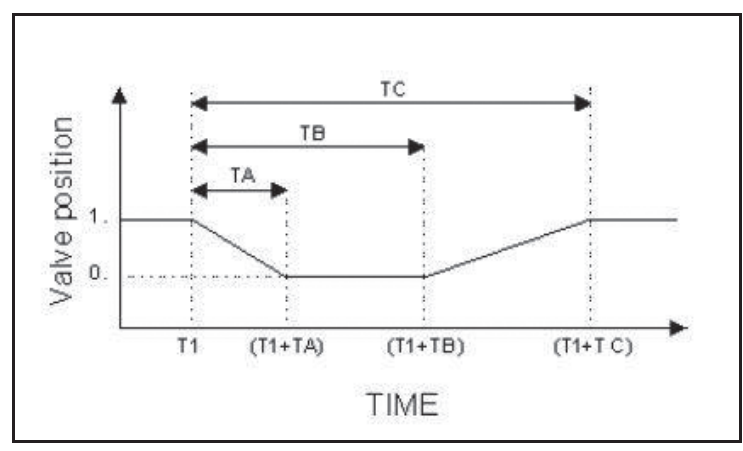

Figure 2 - Valve Actuation Sequence of Typical Fast Valving Scheme [5]

\section{Significance of Speed/Time Settings of FV on Power System Performance}

Performance of the proposed methodology for identification of the optimum settings is demonstrated in this paper using a coal-fired thermal power plant in Sri Lankan power system. Therefore, this section first gives a brief introduction to Sri Lankan power system followed by the significance of the coal-fired thermal plant in meeting the present demand. Subsequently, using practical examples, this section presents how the performance of a system could be affected by different settings if they are made without careful attention.

Sri Lankan power system is currently serving a daily night peak of approximately $2.4 \mathrm{GWh}$. It comprises 4,043 MW of installed generation capacity. The mix of generation sources is Hydro (16\%), Thermal (Thermal and Coal $58 \%$, Independent Power Plant (IPP) Thermal $19 \%$ ) and Non-Conventional Renewable Energy (NCRE) $(7 \%)$. The high voltage transmission network is branched throughout the country with approximately $601 \mathrm{~km}$ of $220 \mathrm{kV}$ lines and nearly $2,310 \mathrm{~km}$ of $132 \mathrm{kV}$ lines, feeding approximately 60 grid substations. The medium voltage network of $33 \mathrm{kV}$ and $11 \mathrm{kV}$ distribution lines are spanned for $32,863 \mathrm{~km}$, electrifying $99.7 \%$ of the nation [6].

Ceylon Electricity Board (CEB) has the sole authority over Sri Lanka's transmission network. The System Control Centre (SCC) operated by $\mathrm{CEB}$ controls the network within safe limits. SCC is used to have only the monitoring facility earlier, but by 2018, it is equipped with supervisory control as well.

Lakvijaya Power Plant (LVPP) is the largest and the first ever coal-fired power plant in Sri Lanka. This plant is located in Norochcholai, Puttalam on the Western shores of the Kalpitiya peninsula. With three units of $300 \mathrm{MW}$ 
capacity, it generates a total power of $900 \mathrm{MW}$ at its peak.

Steam turbine of LVPP consists of three stages, namely, High Pressure (HP) turbines, Intermediate Pressure (IP) turbines and Low Pressure (LP) turbines. The arrangement of turbines and the path of steam flow to these turbines are shown in Figure 3.

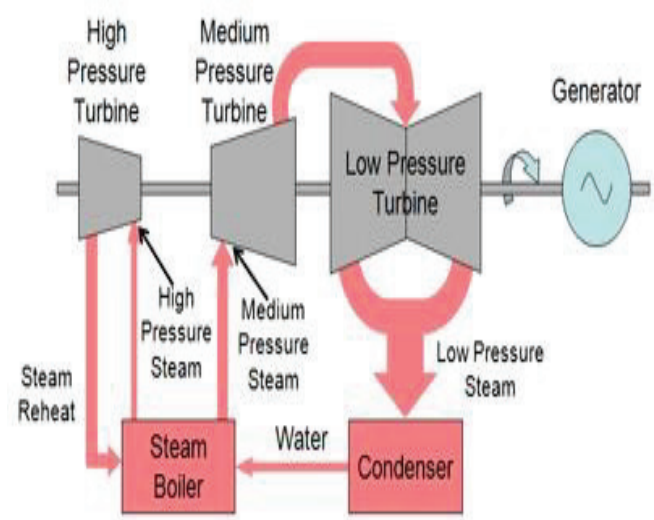

Figure 3 - Arrangement of Steam Turbines at LVPP

The unit which carries out the functions of FV of LVPP steam turbines has been named as the "Over speed Protection Controller (OPC)". As turbine manufacturer states, OPC unit of LVPP mainly focuses on the steam turbine protection on over-speed detection [4]. The only operational difference of FV action and OPC function is that FV controls the steam flow closing the IVs only, while OPC controls all six GVs and IVs. In terms of turbine power, OPC controls $100 \%$ of turbine power and FV controls only $70 \%$ of the total turbine power [7].

The LVPP machines normally operate at their synchronous speed of $3000 \mathrm{rpm}$ and OPC setting has earlier been set to activate when machine speed exceeds $3090 \mathrm{rpm}(103 \%$ of rated $\mathrm{rpm}$ ) [8]. The OPC operation completely shuts all six GVs and the IVs to block the steam flow to the turbine, causing the machine to decelerate. When the speed subsequently decreases to $3030 \mathrm{rpm}$, the OPC resets and GVs and IVs are reopened to let the steam back in. Similarly, the actuation times of GVs and IVs of OPC scheme have been set without doing a careful study.

Sri Lankan power system experienced two blackouts in 2016 which led to system instabilities initiated by transient faults in the transmission system. Both of these incidents made the LVPP machines to over speed and initiated power swings as well as the triggering of the OPC. But the response was not adequate to maintain the stability of the power system. For example, Figure 4 shows the pattern of fluctuations of the system frequency and load (MW) of LVPP machine during the time of OPC activation of all three units in the event on the $25^{\text {th }}$ of February 2016. This fluctuation continued for few minutes and led to trip the machine from boiler dynamics since the OPC function was not capable to maintain the system stability.

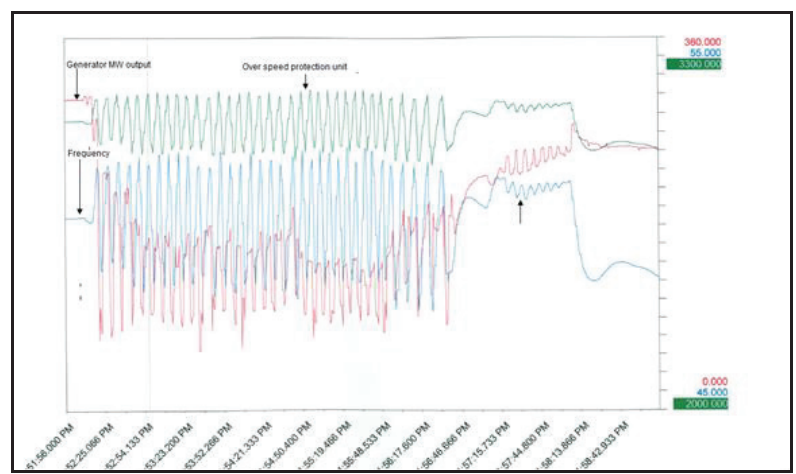

Figure 4 - Frequency/ Load Fluctuation during OPC Activation

Including the two incidents that occurred in 2016, The OPC action of LVPP has been activated at three different occasions historically up to now, as shown in Table 1. Detailed explanation, including the changes of machines speeds and the power outputs of generators during these events, can be found in [9].

\section{Table 1 - OPC Activation Incidents}

\begin{tabular}{|l|l|}
\hline Contingency 01 & 25 February 2016 \\
\hline Date & $\begin{array}{l}\text { A lightning stroke } \\
\text { triggered earth fault } \\
\text { on one phase of the } \\
132 \mathrm{kV} \text { Seethawaka - } \\
\text { Kolonnawa line }\end{array}$ \\
\hline $\begin{array}{l}\text { Behaviour of the } \\
\text { Power System }\end{array}$ & $\begin{array}{l}\text { As a result of these } \\
\text { events, continuous } \\
\text { increase of system } \\
\text { frequency surpassed } \\
\text { the setting of turbine } \\
\text { over-speed limit to } \\
\text { activate Over-Speed } \\
\text { Protection Control } \\
\text { (OPC) function of all } \\
\text { three generators of } \\
\text { LVPP }\end{array}$ \\
\hline Contingency 02 & $\begin{array}{l}\text { The failure has } \\
\text { initiated with the } \\
\text { tripping of Biyagama }\end{array}$ \\
\hline Date & \begin{tabular}{l} 
13 March 2016 \\
\hline Cause
\end{tabular} \\
\hline
\end{tabular}




\begin{tabular}{|l|l|}
\hline \multicolumn{1}{|l|}{} & $\begin{array}{l}\text { 220/L32/33 kV } \\
\text { transformer 01 }\end{array}$ \\
\hline OPC Activation & $\begin{array}{l}\text { Tripping of above } \\
\text { lines and transformers } \\
\text { led to increase system } \\
\text { frequency. increase } \\
\text { Continuous frequency } \\
\text { of system frem } \\
\text { surpassed the setting } \\
\text { of turbine over speed } \\
\text { limit to activate Over } \\
\text { speed Protection } \\
\text { Control (OPC) } \\
\text { function of all three } \\
\text { generators of LVPP }\end{array}$ \\
\hline Contingency 03 & \begin{tabular}{l} 
16 September 2018 \\
\hline Date
\end{tabular} \\
\hline Cause & $\begin{array}{l}\text { Earth Fault at 132 kV } \\
\text { bus of Colombo Sub B }\end{array}$ \\
\hline OPC Activation & $\begin{array}{l}\text { This led to increase of } \\
\text { system frequency. } \\
\text { Continuous increase } \\
\text { of system frequency } \\
\text { surpassed the setting } \\
\text { of turbine over-speed } \\
\text { limit to activate Over } \\
\text { Speed Protection } \\
\text { Control (OPC) } \\
\text { function of unit 2 } \\
\text { steam turbine. }\end{array}$ \\
\hline
\end{tabular}

It is obvious that, once OPC is activated for few minutes, it is very difficult to operate the machine. Best practice to protect the machine is to isolate it from main grid opening synchronous breaker to avoid these fluctuations. This is known as activation of Fast Cut Back (FCB) mechanism. Once FCB activates machine will be isolated from the main grid and will continue to supply only the house load.

To overcome these practical difficulties of plant operation due to OPC activation of all three machines at the same time, three different speeds were set to trigger the OPC function of three machines of LVPP. One of the major changes made was, once OPC function of unit 2 is activated, it will go directly to house load, isolating the unit from main grid by activating FCB. Main reason for this change is to keep at least one machine without getting tripped due to the load fluctuation as a result of OPC activation as experienced in the first two incidents.

There are many research studies evaluating the impact of FV on transient stability, and all this technical literature suggests that it is quite important to determine the steam valve closing time (TA), dead times (TB) and opening times (TC) in coordination with power system transient stability studies. Valve timings cannot be ad-hoc and need to be determined based on power system stability studies. If the valve actuation times are not appropriate, it can lead to aggravation of the system disturbance. The subsequent section describes a generalized procedure to determine these settings based on a system study.

\section{Proposed Methodology}

This section first presents the generalized methodology which can be used to determine the optimum speed and intermediate valve settings of a coal-fired thermal power plant. Then, how the methodology was adopted for the Sri Lankan system is explained.

Each step of the proposed methodology is as follows:

Step 1: Model the power system for electromechanical transient type simulations.

Step 2: Select (N-1) contingencies and rank them according to their probabilities of occurrences.

Step 3: Set the initial timings of Closing Time (TA), Dead Time (TB) and Opening Time (TC) so as to maintain the steady-state stability.

Step 4: Keep two settings at their base case values and change the other setting over a range so that the frequency stability is maintained subsequent to (N-1) contingencies. Thereby, determine the feasible range for the time setting (say TA).

Step 5: Repeat Step 4 for other two time settings and determine their optimum ranges.

Step 6: Set TA, TB, TC time settings at selected values within the optimum ranges determined in Steps 5 and 6 above. Perform transient stability simulations under different contingencies and check the stability of the post-fault system.

Step 7: Determine the optimum settings based on the results of Step 6.

In transient stability studies, the primary concern is the study of the stability of electromechanical oscillations which correspond to speed deviations of synchronous generators from the synchronous speeds. It is the general practice to ignore the stator transients of the synchronous generators for the study of such oscillations and model the network by constant admittances [1]. Therefore, 
it is enough to model a power system in electromechanical type simulation platform such as PSSE, unlike electromagnetic transient type simulation such as PSCAD for the intended study.

Each power system has an identified set of (N1) contingencies in which the behaviour of the post-fault power system is studied with respect to a loss of a single element. These contingencies can be ranked based on their probabilities of occurrence. In this study, it is proposed to vary the time settings (TA, TB, TC) over an acceptable range and verify their appropriateness by selecting different contingencies. The initial values of these time settings can be made so as to maintain the small-signal stability of the power system.

The aforementioned procedure was appropriately changed for the Sri Lankan network by selecting the actually occurred contingencies in the network. The methodology followed is shown in Figure 5.

Sri Lanka power system was modelled using PSS/E (33) software tool. The model developed to analyse the behaviour of OPC function of LVPP includes all the main components of electrical power systems, including synchronous generators, steam governor with OPC and FV actions, excitation systems, power transformers, transmission lines $(220 \mathrm{kV}$ and $132 \mathrm{kV})$, system loads and the electrical network. Then, the developed methodology was used to find the optimum actuation timings for IVs of FV scheme to bring the system back to stability limits from transient condition, once severe fault occurred in transmission system. Each stage of the proposed methodology is explained in detail below.

\section{Stage 1}

In this stage, the OPC activation incident occurred on the $13^{\text {th }}$ of March 2016 (contingency 2 as given in Table 1) was used to find the optimum ranges for valve timings of the Intercept Valves. Figure 2 showed the intermediate valve travel sequence and defined the different valve actuation times. Thereby, TA, TB and TC times were varied to determine the sensitivity of the FV on transient conditions to the actuation times of IVs. The valve actuation timings equal to existing timings of LVPP were identified as the base case. Each one of these three valve times were changed keeping the other two fixed at a time.

The effects of changing closing time (TA), dead time (TB), and opening time (TC) of IVs for the incident occurred on the $13^{\text {th }}$ of March 2016 (contingency 2 as given in Table 1) were analysed one by one as given in following steps.

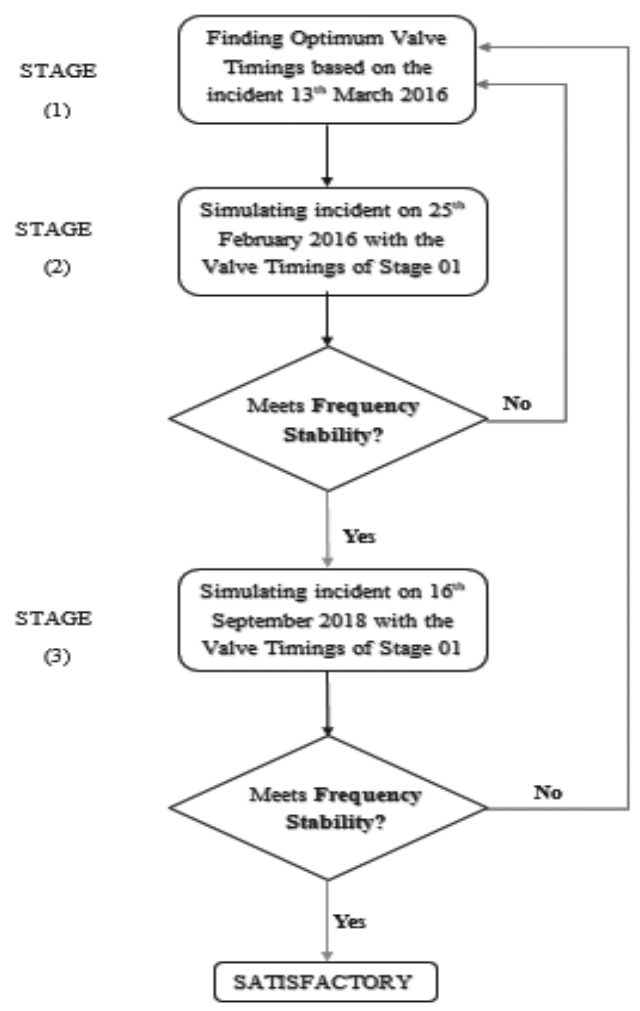

Figure 5 - Proposed Methodology for Sri Lankan Power System

> Step 01 : Check the frequency stability for different TB values and find a range for TB

$>$ Step 02 : Check the frequency stability for different TC values with TB values found in Step 1 and find a range for TC

$>$ Step 03 : Check the frequency stability for different TA values with TB and TC values found in Step 1 and Step 2

$>$ Step 04 : Pick up an appropriate set of timings for $\mathrm{TA}, \mathrm{TB}$ and $\mathrm{TC}$ from time ranges found in Steps 1, 2 and 3

Step 1-Finding TB: TA and TC were initially kept at their existing values of LVPP $(T A=0.15 \mathrm{~s}$ and $\mathrm{TC}=7 \mathrm{~s}$ ) and changed TB from $3 \mathrm{~s}$ to $1 \mathrm{~s}$. It was identified that system frequency stabilizes subsequent to the given contingency for $\mathrm{TB}$ values below 2 s. Figure 6 shows the effect of changing TB from $3 \mathrm{~s}$ to $1 \mathrm{~s}$ on system frequency. 


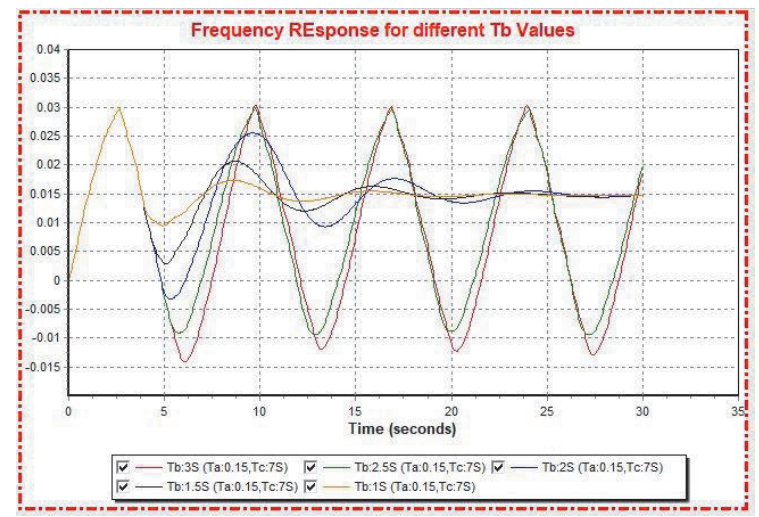

Figure 6 - Frequency Variation (Per Unit) for TB Values between $3 \mathrm{~s}$ and $1 \mathrm{~s}$

TB value was further changed from $2.5 \mathrm{~s}$ to $2 \mathrm{~s}$ in steps of $0.1 \mathrm{~s}$ in order to get precise values for the stable region. It was found that the system gets stable for the TB values below 2.2 sas shown in Figure 7.

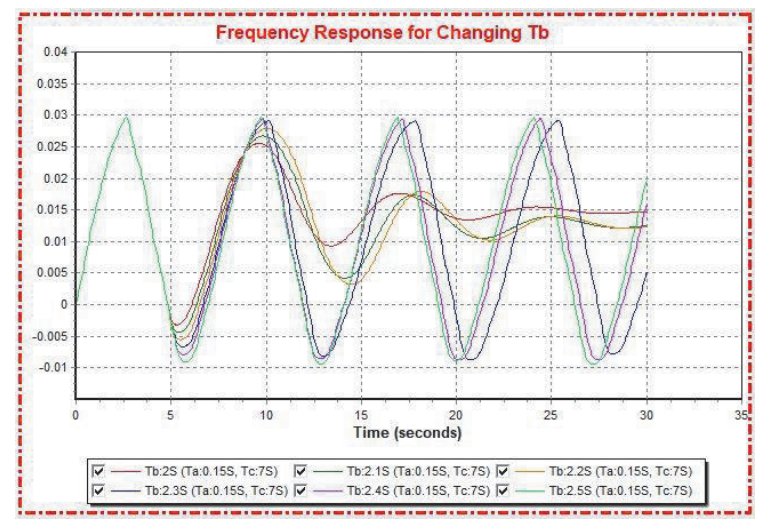

Figure 7 - Frequency Variation (Per Unit) for TB Values between $2.5 \mathrm{~s}$ and $2 \mathrm{~s}$

The results of above two analyses show that the system frequency stabilizes for this particular incident within the range of $1 \mathrm{~s}<\mathrm{TB}<2.2 \mathrm{~s}$

Step 2-Finding TC: Effect of frequency stability for different TC values was analysed in this step for the different TB values within the range found in the Step 1. Stability for different TC values was checked as given in Table 2 . Contingency is same as considered in Stage 1 above (contingency 2 in Table 1).

Table 2 - Different Cases for Finding TC

\begin{tabular}{|l|l|l|l|l|l|}
\hline Cases & $\begin{array}{l}\text { TC/ } \\
\text { TB }\end{array}$ & $\mathbf{5 ~ s}$ & $\mathbf{7 ~ s}$ & $\mathbf{9 ~ s}$ & $\mathbf{1 3 ~ s}$ \\
\hline Case I & $\mathbf{2 ~ s}$ & Stable & Stable & Stable & Unstable \\
\hline Case II & $\mathbf{1 . 5} \mathrm{s}$ & Stable & Stable & Stable & Unstable \\
\hline Case III & $\mathbf{1 ~} \mathrm{s}$ & Stable & Stable & Stable & Stable \\
\hline
\end{tabular}

Simulation results for each case are shown in Figures. 8, 9 and 10.
In Case I, TC was varied between $5 \mathrm{~s}$ and $13 \mathrm{~s}$, keeping $\mathrm{TB}$ at $1 \mathrm{~s}$ which is picked from the stable region of TB found in Step 1. The system stabilizes only for TC values below $9 \mathrm{~s}$ as shown in Figure 8.

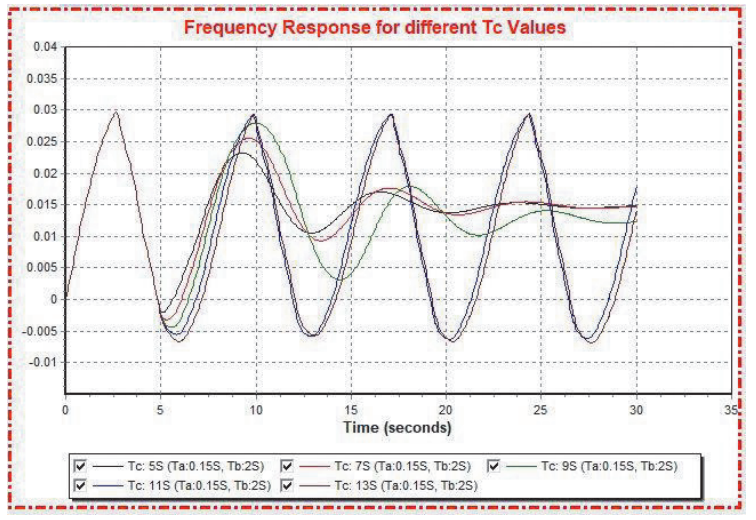

Figure 8 - Case I - Frequency Variation (Per Unit) for Different $T C$ Values for $T B=2 s$

In Case II, TC was varied between $7 \mathrm{~s}$ and $13 \mathrm{~s}$ and keeping $\mathrm{TB}$ at $1.5 \mathrm{~s}$ which is picked from the stable region of TB found in Step 1. The system was stable only for TC values below $9 \mathrm{~s}$ as shown in Figure 9.

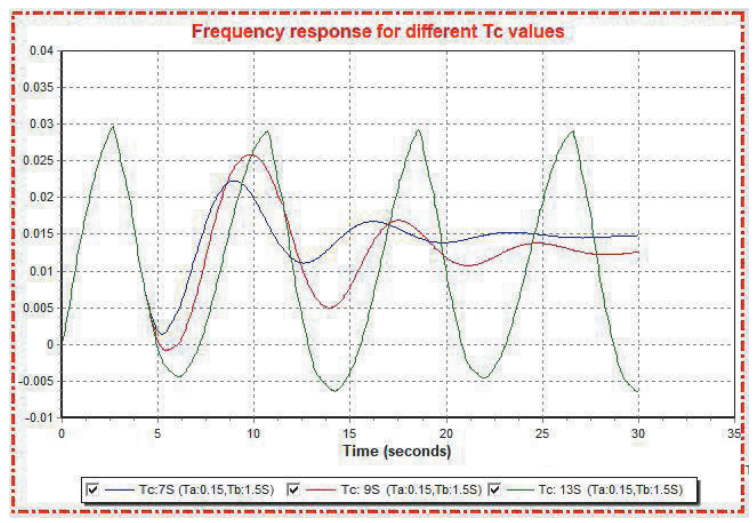

Figure 9 - Case II - Frequency Variation (Per Unit) for Different TC Values for TB=1.5 s

In Case III, TC was varied between $3 \mathrm{~s}$ and $13 \mathrm{~s}$ keeping $\mathrm{TB}$ at $2 \mathrm{~s}$ which is picked from the stable region of TB found in Step 1. The system stabilizes only for TC values below $9 \mathrm{~s}$ as shown in Figure 10.

The results of three cases of the above analysis show that the system frequency stabilizes for this particular incident within the time range of 3 s $<$ TC $<9$ s while keeping TB within the stable time region found in Step 1. 


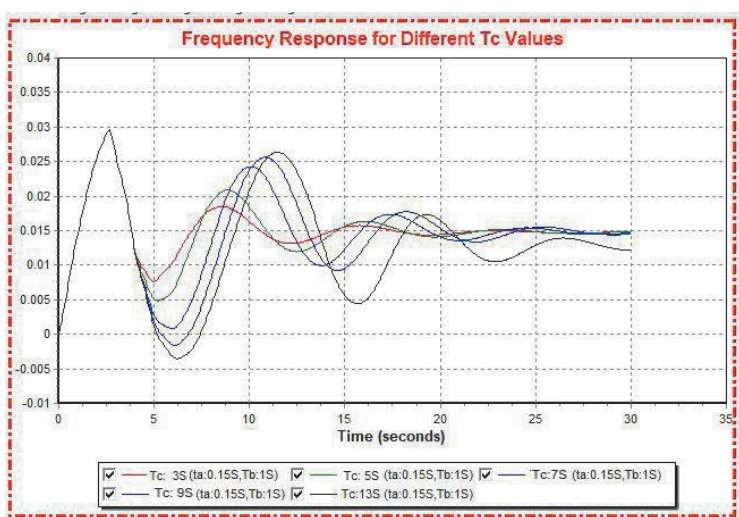

Figure 10 - Case III - Frequency Variation (Per Unit) for Different $\mathrm{TC}$ values for $\mathrm{TB}=1 \mathrm{~s}$

Step 03 - Finding TA: Manufacturer has recommended keeping the closing time of IVs below $0.3 \mathrm{~s}$ in emergency conditions considering the turbine mechanical protection. IV s currently take around $0.15 \mathrm{~s}$ to fully close in emergency conditions. So the possible range for TA values was within $150 \mathrm{~ms}$ and $250 \mathrm{~ms}$. System stability was checked for this range of TA, TB and TC values picked from identified value regions in Step 1 and Step 2.

Figure 11 shows the frequency response for randomly picked up values in this optimum time range of TA.

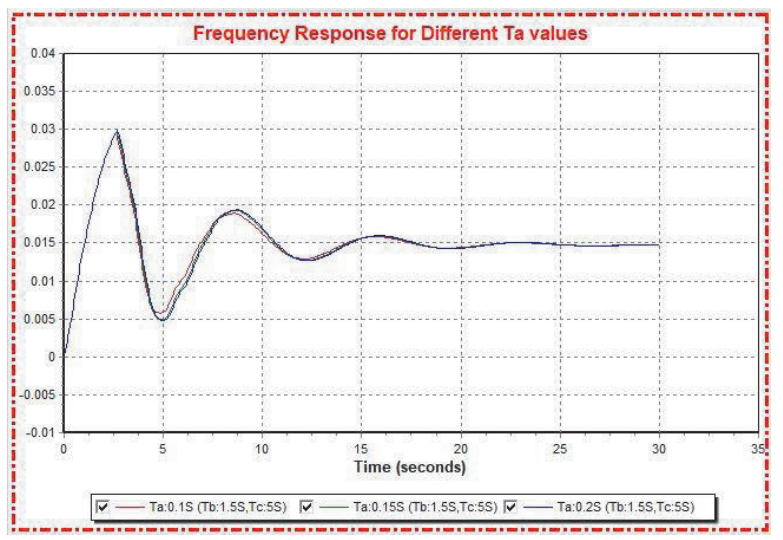

Figure 11 - Frequency Variation (Per Unit) for TA values between $0.1 \mathrm{~s}$ and $0.25 \mathrm{~s}$

From the above three steps in the Stage 1 of the developed methodology, the time ranges shown in Table 3 were found as the optimum time ranges of IVs for FV action to keep system stable under serious disturbances in the power system. Among these optimum time ranges for FV action, one set of values given below were picked as the valve actuation timing for further analysis.
TA $\quad=0.15 \mathrm{~s}$
$\mathrm{TB} \quad=1.5 \mathrm{~s}$
$\mathrm{TC}=5 \mathrm{~s}$

Table 3 - Optimum Valve Actuation Timing ranges for $\mathrm{FV}$

\begin{tabular}{|l|l|l|}
\hline Steps & Findings & $\begin{array}{l}\text { Optimum Time } \\
\text { Range }\end{array}$ \\
\hline Step 1 & $\begin{array}{l}\text { Finding TB } \\
\text { (Dead Time) }\end{array}$ & $1 \mathrm{~s}<\mathrm{TB}<2.2 \mathrm{~s}$ \\
\hline Step 2 & $\begin{array}{l}\text { Finding TC } \\
\text { (Opening } \\
\text { Time) }\end{array}$ & $3 \mathrm{~s}<\mathrm{TC}<9 \mathrm{~s}$ \\
\hline Step 3 & $\begin{array}{l}\text { Finding TA } \\
\text { (Closing Time) }\end{array}$ & $0.1 \mathrm{~s}<\mathrm{TA}<0.25 \mathrm{~s}$ \\
\hline
\end{tabular}

\section{Stage 2}

The values found for valve timings in Stage 1 were used to simulate the incident occurred on the $25^{\text {th }}$ of February 2016 (contingency 1 as given in the Table 1) enabling FV action. The actually occurred frequency response and the simulated response with the determined time settings are shown in Figure 12. It is seen that the system has stabilized without sever fluctuation for the valve actuation timings picked up from Stage 1.

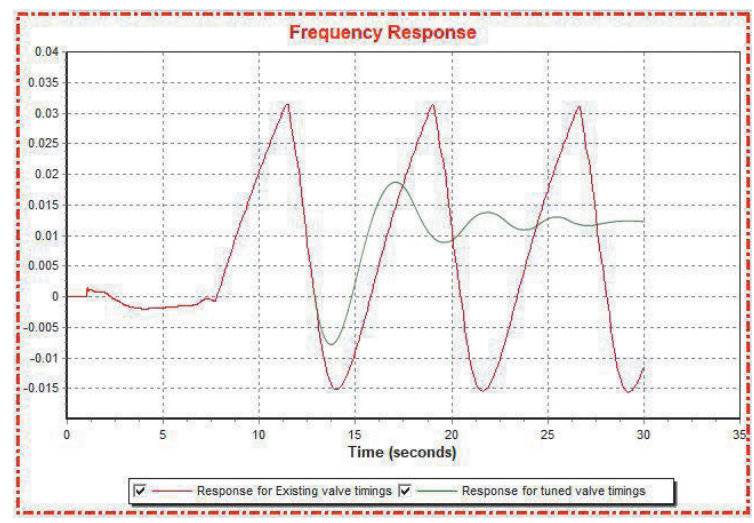

Figure 12 - Frequency Variation (Per Unit) for Existing and Prosed time Settings under Contingency 1

\section{Stage 03}

The values found for valve timings in the Stage 1 were further used to simulate the incident happened on the $16^{\text {th }}$ of September 2018 (contingency 3 as given in Table 1). Same incident was simulated enabling FV action with the valve actuation timings found in the Stage 1. The results are shown Figure 13. 


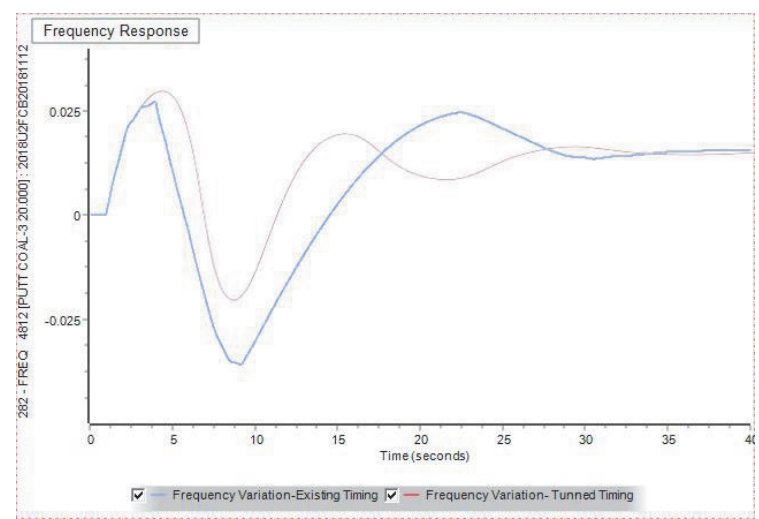

Figure 13 - Frequency Variation (Per Unit) for Existing and Prosed time Settings under Contingency 3

The system has again stabilized for the incident happened on the $16^{\text {th }}$ of September 2018 (contingency 3 as given in Table 1) without severe fluctuation for the valve actuation timings picked up from Stage 1.

\section{Results and Analysis}

From the results of this study and manufacturer recommendations for $\mathrm{TA}$, the values given in Table 4 and 5 are recommended for the fast valving settings of the coal fired thermal generator unit considered in this study.

Table 4 - Proposed Speed settings for FV

\begin{tabular}{|c|c|c|}
\hline & $\begin{array}{c}\text { FV Enable } \\
\text { Speed (rpm) }\end{array}$ & $\begin{array}{c}\text { FV Disable } \\
\text { Speed (rpm) }\end{array}$ \\
\hline Unit 01 & 3090 & 3030 \\
\hline Unit 02 & 3090 & 3030 \\
\hline Unit 03 & 3090 & 3030 \\
\hline
\end{tabular}

Table 5 - Proposed Intermediate Valve Actuation Timings for FV

\begin{tabular}{|l|l|l|}
\hline $\begin{array}{c}\text { Intermediate } \\
\text { Valve } \\
\text { Actuation } \\
\text { Timing }\end{array}$ & \multicolumn{1}{|c|}{ Range } & \multicolumn{1}{|c|}{$\begin{array}{c}\text { Optimum } \\
\text { Settings }\end{array}$} \\
\hline TA & $0.1 \mathrm{~s}<\mathrm{TA}<0.25 \mathrm{~s}$ & $0.15 \mathrm{~s}$ \\
\hline TB & $1 \mathrm{~s}<\mathrm{TB}<2.2 \mathrm{~s}$ & $1.5 \mathrm{~s}$ \\
\hline TC & $3 \mathrm{~s}<\mathrm{TC}<9 \mathrm{~s}$ & $5 \mathrm{~s}$ \\
\hline
\end{tabular}

After determining the optimum time ranges for the actuation timings of IVs, the effects of changing TA, TB and TC on frequency stability of the power system were further investigated. The system frequency responses with different values of TA, TB and TC from optimum time ranges found have been examined here.

\subsection{Effect of Changing TA within the Recommended Time Range}

Due to the manufacturer recommendations for Time TA taking turbine mechanical protection into consideration, the time range for TA of IVs is very narrow. The system stability was checked for the incident happened on the $13^{\text {th }}$ March 2016 (contingency 1) within the recommended range of TA $(0.1 \mathrm{~s}<\mathrm{TA}<0.25 \mathrm{~s})$. Figure 14 shows the frequency responses for three different TA values $(0.1 \mathrm{~s}, 0.15 \mathrm{~s}$ and $0.2 \mathrm{~s})$ within the optimum range. The system was stable for this recommended range of TA.

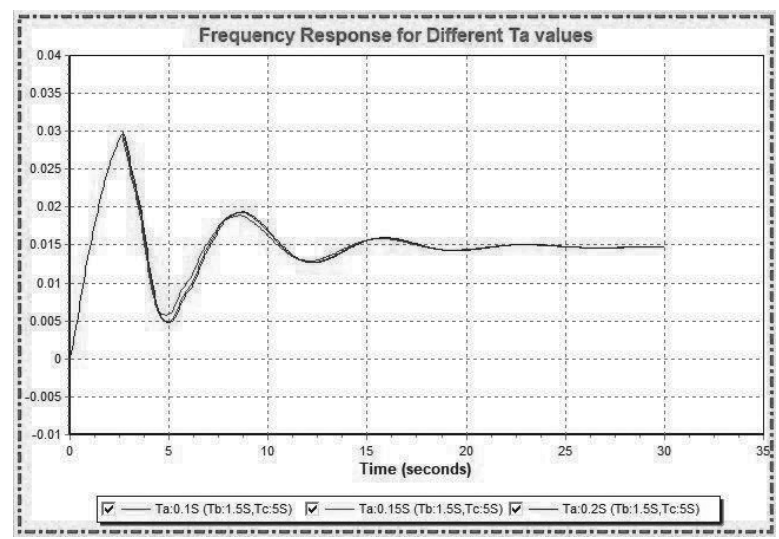

Figure 14 - Frequency Variation (Per Unit) for Different TA within Proposed Optimum Time Range

\subsection{Effect of Changing TB within the Recommended Range}

TB has a direct relationship with the accumulation of steam in the reheater which will be higher when TB is increased. The stored steam in the reheater produces more mechanical driving power as the intercept valve reopens completely. The release of stored steam in the reheater causes to increase the mechanical driving power from the nominal value and it affects the subsequent swings and the transient stability of the system.

Three different TB values (1 s, 1.5 s, 2 s) were randomly picked from the recommended timing range of $\mathrm{TB}(1 \mathrm{~s}<\mathrm{TB}<2.2 \mathrm{~s})$ to determine the effect of different TB values. System was stable for the incident happened on the $13^{\text {th }}$ March 2016 (contingency 1) within recommended range of $\mathrm{TB}$ as shown in Figure 15. 


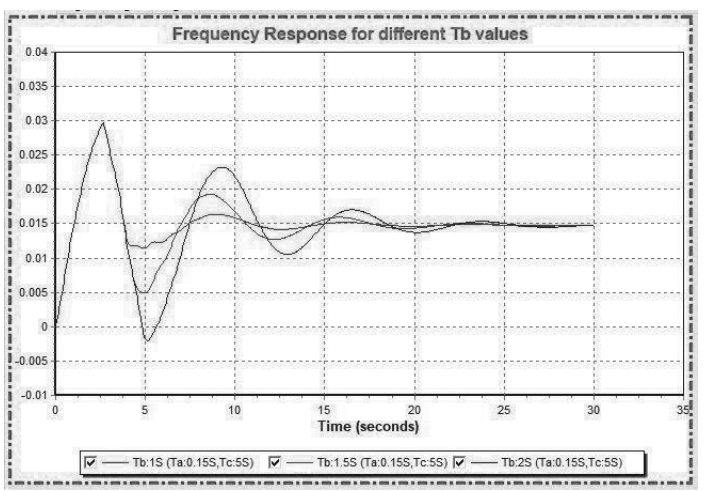

Figure 15 - Frequency Variation (Per Unit) for Different TB of Proposed Optimum Time Range

As explained when TB is increased, the accumulation of steam in reheater considerably affects the second swing stability as shown in Figure 15. The second swing is much controllable when the dead time reduced to nearly $1 \mathrm{~s}$ from $2 \mathrm{~s}$.

\subsection{Effect of Changing TC within the Recommended Range}

The valve actuation time for different reopening times (TC) were considered in this case. When TA and TB are not varied, the mechanical driving power decay occurs at the same rate for all values of TC within the range. Three different TC values ( $3 \mathrm{~s}, 5 \mathrm{~s}$ and $7 \mathrm{~s}$ ) were randomly picked from the recommended timing range of TC $(3 \mathrm{~s}<\mathrm{TB}<9 \mathrm{~s})$ to determine the effect of different TC values. System gets stable for the incident happened on the $13^{\text {th }}$ March 2016 (contingency 1) within the recommended range of TC as shown in Figure 16.

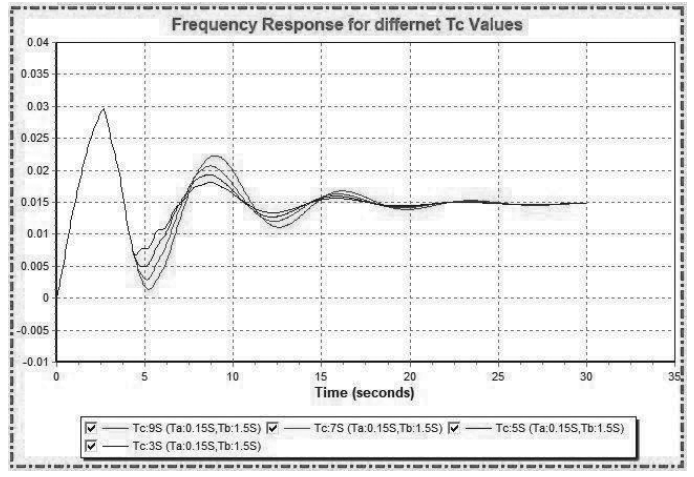

Figure 16 - Frequency Variation (Per Unit) for Different TC within the Optimum Time Range

The change of TC varies the rate of rise of mechanical power to the nominal value. As per Figure 16, it is clear that TC has no effect on first swing stability of the system but on the second swing and subsequent swing stability. This is due to time taken for reopening of IVs and it decides the accumulation of steam in the reheater and rate of release of the accumulated steam.

As per the results of these simulations, closing time (TA) mainly affects the first swing but dead time (TB) has larger effect on the second swing. Also, the valve opening time (TC) has effect on the stability of second swing and subsequent swings but not on first swing stability.

\subsection{Comparing FV and OPC}

The effect of OPC and FV were compared separately for the incident occurred on the $13^{\text {th }}$ of March 2016 (contingency 1) with the optimum valve actuation timings found above.

As shown in Figure 17, the frequency oscillations damp faster with FV action compared to OPC. Therefore, FV is recommended to use as a transient stability enhancement element of steam turbines.

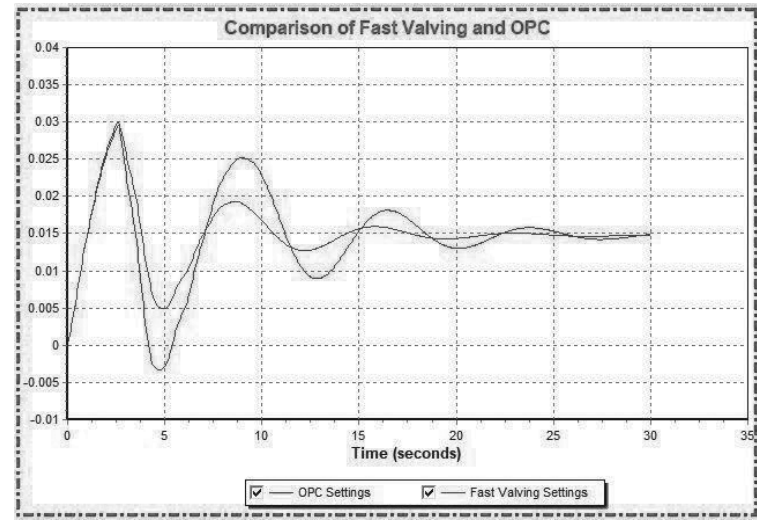

Figure 17 - Comparison of Frequency Variation (Per Unit) under OPC and FV Action of LVPP

\section{Conclusions}

This paper presented a generalized procedure to determine optimum settings for FV action of a coal-fired thermal power plant. The procedure was validated using actual incidents happened in the Sri Lankan power system.

This study demonstrated that the use of FV has more controllability over transient stability than OPC. The results of the study carried out on these two schemes clearly showed that the effectiveness of $\mathrm{FV}$ in improving transient stability is higher than OPC and controlling $70 \%$ of the turbine power is enough to enhance the transient stability under large disturbance of the system. 
The simulation results of this study have clearly showed that finding the optimum time settings for valve actuations of FV is of paramount importance to enhance the transient stability. It is further proved that the possibility of a first swing, second swing and subsequent swing instability are very high under a large disturbance of the power system when these valve actuation timings are out of the range. The results of this study finally showed that all three incidents which triggered OPC function of the case study could be controlled without leading to a blackout by enabling the FV schemes with the proposed settings.

\section{References}

1. Kundur, P., Power System Stability and Control, McGraw-Hill, Inc, 1994.

2. Ramnarayan Patel, Bhatti T. S. and Kothari, D. P., "A Modified Approach to Transient Stability Enhancement with Fast Valving and Braking Resistor Applications," International Journal of Electrical Power E Energy Systems, vol. 28, no. 10, pp. 729-738, 2006.

3. Prioste, F. B., Mendes, P. P. C., and Ferreira, C., "Power System Transient Stability Enhancement by Fast Valving," in IEE/PES Transmission $\mathcal{E}$ Distribution, 2004.

4. Ministry of Power and Renewable Energy, "Findings of the Committee Appointed to Investigate Power System Failure on 25th February 2016," GoSL, 2016.

5. Neplan AG, “TURBINE-GOVERNOR MODELS," Küsnacht $\mathrm{ZH}$.

6. Ministry of Power and Renewable Energy, "Performance 2017 and Programmes for 2018," GoSL, 2017.

7. Jan Machowski, Adam Smolarczyk and Bialek, J. W., "Power System Transient Stability Enhancement By Cordinated Fast Valving and Excitation Control of Synchronous Generator," in CIGRE Symposium on Working Plant and Systems Harder, London, 1999.

8. Ceylon Electricity Board, 2*300 MW Puttalam Coal Power Project (Phase II), Operation and Maintenance Manual, , 2016.

9. Karunanayakage Janaka Lakmewan, "Study of the settings of Over Speed Protection Control Unit of LVPP Steam Turbines for Enhancing Frequency Stability of Sri Lanka Power System", MSc Thesis, University of Moratuwa, Sri Lanka 2019 